BMJ Paediatrics Open

\title{
Paediatric emergency department dog bite attendance during the COVID-19 pandemic: an audit at a tertiary children's hospital
}

John S P Tulloch (D) , ${ }^{1}$ Simon Minford, ${ }^{2}$ Vicky Pimblett, ${ }^{2}$ Matt Rotheram, ${ }^{3}$ Robert M Christley, ${ }^{1,4}$ Carri Westgarth ${ }^{1}$

To cite: Tulloch JSP, Minford S, Pimblett $\mathrm{V}$, et al. Paediatric emergency department dog bite attendance during the COVID-19 pandemic: an audit at a tertiary children's hospital. BMJ Paediatrics Open 2021;5:e001040. doi:10.1136/ bmjpo-2021-001040

Received 27 January 2021 Revised 26 February 2021 Accepted 20 March 2021
Check for updates

(c) Author(s) (or their employer(s)) 2021. Re-use permitted under CC BY-NC. No commercial re-use. See rights and permissions. Published by BMJ.

${ }^{1}$ Institute of Infection, Veterinary and Ecological Sciences, University of Liverpool,

Liverpool, UK

${ }^{2}$ Department of Plastic Surgery, Alder Hey Children's NHS

Foundation Trust, Liverpool, UK ${ }^{3}$ Emergency Department, Alder Hey Children's NHS Foundation Trust, Liverpool, UK

${ }^{4}$ Dogs Trust, London, UK

Correspondence to Dr John S P Tulloch; jtulloch@ liverpool.ac.uk

\section{ABSTRACT}

Background Responses to the COVID-19 pandemic include strict public health measures, such as national lockdowns. During these measures, paediatric emergency department attendances have declined and the prevalence of presenting complaints has changed. This study sought to identify whether dog bite attendance and victim demographics changed during COVID-19 public health measures.

Methods An audit was conducted of emergency department attendance data from a UK tertiary paediatric hospital between January 2016 and September 2020. Dog bite attendance and victim demographics were explored using $\chi^{2}$ tests and multivariable Poisson regression. The mean monthly percentage of attendance due to dog bites in 2020 was compared against predicted percentages based on previous years' data.

Results Dog bite attendance rose in conjunction with the introduction of COVID-19 public health measures and reached a peak in July 2020 (44 dog bites, 1.3\% of all attendances were due to dog bites). This was a threefold increase in dog bite attendance. By September 2020, attendance had returned to normal. The demographic profile of child dog bite victims remained the same. Boys had the highest attendance rates in 7-12 year-olds, girls in 4-6year-olds. Girls showed higher attendance rates in the summer, while boys' attendance rates were constant throughout the year. COVID-19 public health measures were associated with a $78 \%$ increase in attendance for boys and a $66 \%$ increase in girls.

Conclusions COVID-19 national public health measures were associated with an increase in paediatric emergency department dog bite attendance, and may be due to increased child exposure to dogs via 'stay at home' orders and school closures. National lockdowns are likely to continue globally throughout the COVID-19 pandemic; this is likely to result in more dog bites. Urgent public health communication and injury prevention strategies are needed to help prevent these avoidable injuries.

\section{INTRODUCTION}

The COVID-19 global pandemic caused by SARS-CoV-2 has affected medicine and public health in a multitude of unforeseen ways. One of these was the significant

\section{What is known about the subject?}

Children are frequent dog bite victims.

Most children are bitten in the home by a dog that they know.

- In adults, men are more likely to be bitten than women.

\section{What this study adds?}

Emergency attendance for dog bites to children was three times higher than expected during COVID-19 public health measures

- The victim profile, regarding the age and sex of the child, did not change.

- COVID-19 public health measures, such as lockdowns and school closures, may result in increased dog bites.

reduction in patient attendance at paediatric emergency departments during COVID-19 national lockdowns. ${ }^{1} 2$ Absolute attendance reduced between $27 \%$ and $72 \%, 2^{2}$ though this reduction was not seen across all presenting complaints. For example, attendance for trauma has increased and decreased, dependent on the reporting hospital. ${ }^{1-3}$ One trauma of increasing concern is dog bites.

Dog bite hospital admission rates across England have tripled in adults between 1998 and 2018, yet remained stable in children, with a mean child annual admission rate of $14.4 \mathrm{dog}$ bite hospital admissions per 100000 population per year. ${ }^{4}$ Both sexes have their highest admission rates in childhood, peaking between 5 and 14 years old for boys and 5 and 9 years old for girls.

The majority of dog bite injuries to children occur to the head ${ }^{5-8} ; 73.3 \%$ in English hospital admissions. In Canadian paediatric emergency departments, $25 \%$ of bites were classified as severe, $15 \%$ of victims were 
admitted, $7 \%$ needed operations and $0.3 \%$ resulted in fatalities. ${ }^{9}$ Children are over-represented in fatal $\operatorname{dog}$ attacks; in the USA, $55.6 \%$ of victims were less than 10 years old, ${ }^{10}$ in Canada $86 \%$ were under 12 years old, ${ }^{11}$ while in Europe 16\% were less than 10, with 3\% less than a year old. ${ }^{12}$ UK fatality numbers are unknown. Even with excellent management of wounds, the physical and psychological consequences may be long lasting, ${ }^{13} 14$ with $70 \%$ of parents of dog bite victims having reported behavioural concerns in their children as a sequela of the bite. $^{14}$

During the COVID-19 pandemic, many public health measures directly affected children, primarily the implementation of national lockdowns, 'stay at home' orders, the restriction of socialisation outside their household unit and the closure of schools. ${ }^{15}{ }^{16}$ Such measures resulted in children spending more time than usual at home. Previous research has demonstrated that dogs provided people and families with many positive benefits in lockdown by reducing loneliness and improving wellbeing. ${ }^{17}$ However, it is known that the majority of child dog bite victims are bitten inside the home, ranging from $41 \%$ to $91 \%,{ }^{4} 81819$ and most dogs involved are known to the victim. ${ }^{9}{ }^{18} \mathrm{We}$, and others, have theorised that the increased time at home, and resultant increased contact time with a pet dog, could lead to more dog bites and a subsequent increase in dog bite attendances at paediatric emergency departments. ${ }^{20}$ The aim of this study was to understand the impact that English COVID-19 public health measures had on emergency department dog bite attendance in a paediatric hospital.

\section{METHODS}

An audit of emergency department records was performed at Alder Hey Children's Hospital to identify trends in the number of dog bites and the percentage of attendances due to dog bites, to explore patient demographics between 1 January 2016 and 30 September 2020 and identify any impact associated with the COVID-19 public health measures. Alder Hey Children's Hospital has one of the busiest paediatric emergency departments in the UK. It primarily serves the children of Liverpool and surrounding areas, but major traumas are received from North West England, North Wales and the Isle of Man.

Anonymised data were collected from hospital patient electronic health records. These contain standard information regarding clinical and safeguarding aspects of the child presenting to the emergency department. The following variables were captured for all attendees of the emergency department: date of attendance, age, sex and whether a dog bite was their reason for attendance (as a binary term). Monthly dog bite attendance counts were plotted, alongside overall attendance figures. The mean monthly number of dog bites prior to, and during, the COVID-19 public health measures was compared using a $\chi^{2}$ test, and a linear trend with age further evaluated using a $\chi^{2}$ test for trend (also known as a Cochran-Armitage test for trend).

The monthly percentage of attendances due to dog bites was calculated for the whole audit period, with associated CIs calculated using Byar's method. Monthly attendance percentages were smoothed using LOESS (locally estimated scatterplot smoothing) methods. ${ }^{22}$ Monthly attendance percentages for 2020 were predicted based on monthly data from 2016 to 2019 using the ETS (error, trend and seasonality) method. ${ }^{23-25}$

For this analysis, a binary variable ('COVID-19 Public Health Measures') was assigned to each patient to indicate whether any national COVID-19 public health measures were in place at the time of attendance; this variable was assigned the value of 1 for attendances within the months March to September $2020,{ }^{15} 16$ and the value 0 otherwise. To compare the demographics (sex and age) of dog bite victims during and outside of COVID-19 public health measures, $\chi^{2}$ tests were performed. Age groups were defined as infants $(<12$ months old), toddlers ( $1-3$ years old), early childhood (4-6 years old), middle childhood (7-12 years old) and adolescents (13-17 years old) ${ }^{26}$

Interrupted Poisson regression time series was performed to assess the following variables' association with monthly attendances for dog bites: time (a linear term, with each unit equating to an individual month), month of the year, sex, age group and COVID-19 public health measures. The number of dog bite victims per month was used as the numerator, while the dominator was the emergency department attending population. Sex-specific multivariable models were created. Interaction between age and sex often occurs when analysing healthcare data. Thus, presenting sex-stratified models provided clarity to our results, in addition to delivering clear sex disaggregated data as recommended by the WHO ${ }^{27}$ Each model used attendance data for each specified sex as their dominator. Substantive knowledge was used to select the models with the best fit (only these will be presented). All models were checked for the presence of any interaction terms. Goodness-of-fit $\chi^{2}$ tests for Poisson models were used to assess model performance.

All statistical analyses were carried out using $\mathrm{R}$ language (V.3.5.3). Results were deemed statistically significant where $\mathrm{p}<0.05$.

\section{Patient and public involvement}

Patients or the public were not involved in this research.

\section{RESULTS}

Between 1 January 2016 and 30 September 2020, a total of 919 individuals attended Alder Hey Children's Hospital's emergency department for a dog bite; over the study period $0.33 \%$ (95\% CI 0.31 to 0.36 ) of all attendances were due to dog bites.

Prior to March 2020, the mean monthly total emergency department attendance was 5035 (95\% CI 4899 to 5171). The lowest monthly total number of attendances 


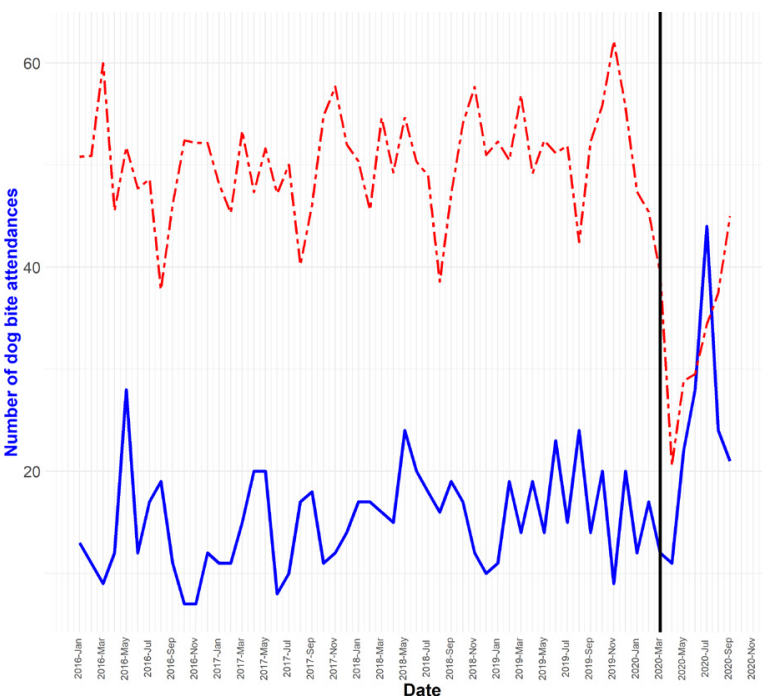

Figure 1 Monthly dog bite attendance and overall hospital (2016-2020). Blue line, and left-hand axis=dog bite attendance. Red dashed line, and right-hand axis=total emergency department attendance. Vertical black line=start of COVID-19 public health measures.

was recorded in April $2020(\mathrm{n}=2056)$, this represents a 2.45 times reduction (figure 1 ). The mean monthly dog bite attendance was 15 cases (95\% CI 14 to 16), the highest monthly dog bite attendance was in July 2020 ( $n=44)$, an almost threefold increase (ratio: 2.93) compared with mean monthly dog bite attendance. Overall, there was a significant increase in the mean monthly number of dog bite attendances when COVID-19 public health measures were applied (table 1 ).

There was no significant difference in the proportion of males and females attending based on whether they attended during COVID-19 public health measures emergency department attendance in a UK paediatric

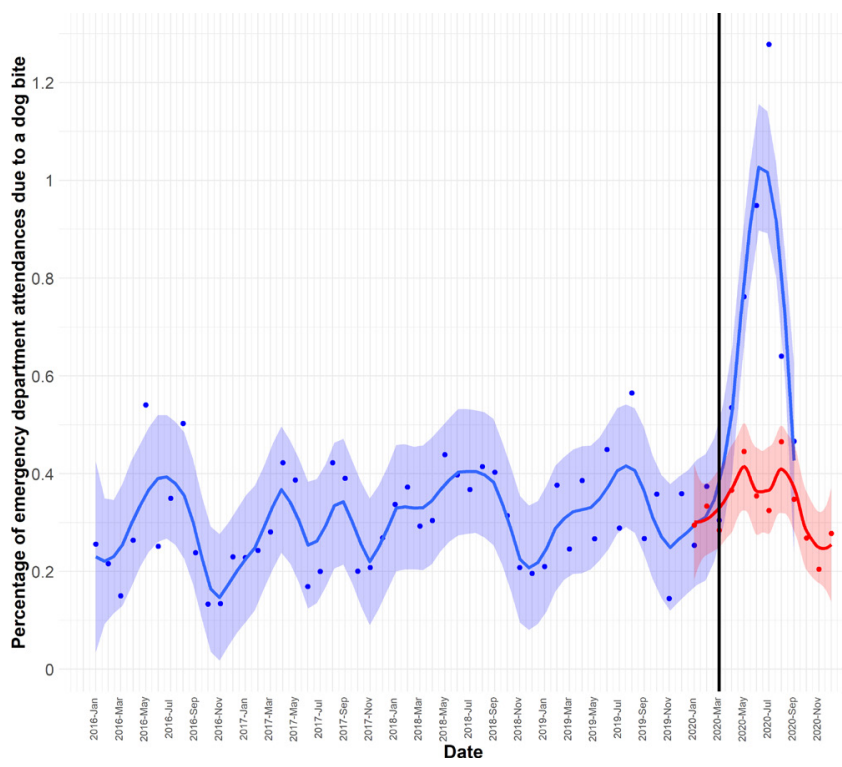

Figure 2 Percentage of monthly emergency department attendances due to dog bites for a UK paediatric hospital (2016-2020). Blue line=raw data. Red line=predicted data for 2020 based on 2016-2019 data. Vertical black line=start of COVID-19 public health measures.

or not $\left(\chi^{2}=0.17, \mathrm{p}=0.68\right)$, nor was there a difference in the proportion of ages attending $\left(\chi^{2}=3.92, \mathrm{p}=0.42\right)$ or evidence of a linear effect of age (trend $\chi^{2}=0.13, \mathrm{p}=0.71$ )

The monthly percentage of attendances due to dog bites prior to 2020 revealed a consistent yet fluctuating pattern, ranging from $0.13 \%$ to $0.57 \%$, with a mean monthly percentage of 0.31 (95\% CI 0.28 to 0.34 ) (figure 2). The monthly percentages in 2020 deviated from the projected data from May to August, peaking in July with $1.28 \%$ (95\% CI 0.94 to 1.70 ) of all attendances due to dog bites. This peak reflected a quadrupling
Table 1 Demographics of paediatric dog bite victims stratified by the presence of national COVID-19 public health measures

\section{COVID-19 public health measures absent (January 2016 to February 2020)}

\begin{tabular}{|c|c|c|c|}
\hline Sex & & & $p=0.68$ \\
\hline Male & $51.9 \%(n=393)$ & $53.7 \%(n=87)$ & \\
\hline Female & $48.1 \%(n=364)$ & $46.3 \%(n=75)$ & \\
\hline Age & & & $\begin{array}{l}\chi^{2} p=0.42 \\
\text { Trend } \chi^{2} p=0.71\end{array}$ \\
\hline Infant (<12 months) & $3.6 \%(n=27)$ & $1.9 \%(n=3)$ & \\
\hline Toddler (1-3 years) & $26.6 \%(n=201)$ & $26.5 \%(n=43)$ & \\
\hline Early child (4-6 years) & $21.9 \%(n=166)$ & $27.2 \%(n=44)$ & \\
\hline Middle child (7-12 years) & $33.4 \%(n=253)$ & $33.3 \%(n=54)$ & \\
\hline Adolescent (13-17 years) & $14.5 \%(n=110)$ & $11.1 \%(n=18)$ & \\
\hline Total & 757 & 162 & \\
\hline $\begin{array}{l}\text { Mean number of dog bites per } \\
\text { month }(95 \% \mathrm{Cl})\end{array}$ & 15.14 (14.09 to 16.25$)$ & 23.14 (19.78 to 26.92$)$ & $p<0.001$ \\
\hline
\end{tabular}

COVID-19 public health measures present (March 2020 to September (March

p value 
Table 2 Univariable and multivariable Poisson analysis of monthly paediatric dog bite attendance rates in an emergency department

\begin{tabular}{|c|c|c|c|c|c|c|}
\hline \multirow[b]{2}{*}{ Variable } & \multicolumn{2}{|c|}{ Univariable analysis } & \multicolumn{2}{|c|}{$\begin{array}{l}\text { Female } \\
\text { multivariable model }\end{array}$} & \multicolumn{2}{|c|}{$\begin{array}{l}\text { Male } \\
\text { multivariable model }\end{array}$} \\
\hline & ARR (95\% Cl) & $\mathrm{p}$ value & ARR $(95 \% \mathrm{Cl})$ & $P$ value & ARR $(95 \% \mathrm{Cl})$ & $\mathrm{p}$ value \\
\hline \multicolumn{7}{|c|}{ COVID-19 public health measures (Ref=Absent) } \\
\hline Present & 2.29 (1.93 to 2.71$)$ & $<0.001$ & 1.66 (1.18 to 2.32$)$ & $<0.001$ & 1.78 (1.29 to 2.44$)$ & $<0.001$ \\
\hline Time (linear) & 1.01 (1.01 to 1.02$)$ & $<0.001$ & 1.00 (1.00 to 1.01$)$ & 0.38 & 1.01 (1.00 to 1.01$)$ & 0.03 \\
\hline \multicolumn{7}{|l|}{ Year (Ref=2016) } \\
\hline 2017 & $1.06(0.85$ to 1.32$)$ & 0.59 & N/A & & N/A & \\
\hline 2018 & 1.26 (1.02 to 1.55$)$ & 0.03 & N/A & & N/A & \\
\hline 2019 & 1.20 (0.98 to 1.48$)$ & 0.08 & N/A & & N/A & \\
\hline 2020 & 2.20 (1.78 to 2.71$)$ & $<0.001$ & N/A & & N/A & \\
\hline \multicolumn{7}{|l|}{ Month (Ref=January) } \\
\hline February & $1.23(0.88$ to 1.72$)$ & 0.23 & 1.69 (1.02 to 2.88$)$ & 0.05 & 0.95 (0.60 to 1.48$)$ & 0.81 \\
\hline March & 0.97 (0.69 to 1.37$)$ & 0.87 & 1.27 (0.75 to 2.19$)$ & 0.38 & 0.60 (0.37 to 0.96$)$ & 0.04 \\
\hline April & 1.41 (1.02 to 1.97$)$ & 0.04 & 1.66 (0.99 to 2.84 ) & 0.06 & 1.08 (0.70 to 1.67$)$ & 0.73 \\
\hline May & 1.76 (1.29 to 2.40$)$ & $<0.001$ & 2.26 (1.41 to 3.76$)$ & $<0.01$ & 1.10 (0.73 to 1.67$)$ & 0.65 \\
\hline June & 1.57 (1.14 to 2.17$)$ & $<0.01$ & 1.68 (1.01 to 2.86 ) & 0.05 & 1.12 (0.74 to 1.70$)$ & 0.60 \\
\hline July & 1.73 (1.27 to 2.37 ) & $<0.001$ & 2.05 (1.26 to 3.42 ) & $<0.01$ & 1.11 (0.74 to 1.69$)$ & 0.61 \\
\hline August & 1.98 (1.45 to 2.72 ) & $<0.001$ & 2.28 (1.39 to 3.83 ) & $<0.01$ & 1.26 (0.83 to 1.93 ) & 0.28 \\
\hline September & 1.36 (0.99 to 1.90$)$ & 0.06 & 1.75 (1.06 to 2.96 ) & 0.03 & 0.75 (0.48 to 1.17$)$ & 0.20 \\
\hline October & 0.99 (0.69 to 1.41$)$ & 0.94 & 1.28 (0.73 to 2.27$)$ & 0.39 & 0.84 (0.52 to 1.34$)$ & 0.47 \\
\hline November & 0.68 (0.45 to 1.00$)$ & 0.05 & 1.08 (0.60 to 1.93 ) & 0.81 & 0.48 (0.27 to 0.82$)$ & 0.01 \\
\hline December & 1.03 (0.72 to 1.48$)$ & 0.86 & 1.05 (0.57 to 1.91$)$ & 0.87 & 1.06 (0.67 to 1.66$)$ & 0.81 \\
\hline \multicolumn{7}{|l|}{ Sex (Ref=Female) } \\
\hline Male & $0.91(0.80$ to 1.03$)$ & 0.14 & $\mathrm{~N} / \mathrm{A}$ & & N/A & \\
\hline \multicolumn{7}{|l|}{$\begin{array}{l}\text { Age (Ref=Toddler, } 1-3 \text { years } \\
\text { old) }\end{array}$} \\
\hline Infant (<12 months) & 0.19 (0.13 to 0.28$)$ & $<0.001$ & 0.17 (0.09 to 0.29$)$ & $<0.001$ & 0.21 (0.12 to 0.35$)$ & $<0.001$ \\
\hline $\begin{array}{l}\text { Early childhood ( } 4-6 \text { years } \\
\text { old) }\end{array}$ & 1.75 (1.45 to 2.10$)$ & $<0.001$ & 1.89 (1.46 to 2.45 ) & $<0.001$ & 1.53 (1.17 to 2.00$)$ & $<0.01$ \\
\hline $\begin{array}{l}\text { Middle childhood (7-12 } \\
\text { years old) }\end{array}$ & 1.70 (1.44 to 2.01$)$ & $<0.001$ & 1.44 (1.13 to 1.85 ) & $<0.01$ & 1.83 (1.46 to 2.31$)$ & $<0.001$ \\
\hline Adolescent (13-17 years old) & 1.30 (1.05 to 1.61$)$ & 0.01 & 0.94 (0.68 to 1.30$)$ & 0.72 & 1.65 (1.23 to 2.19$)$ & $<0.001$ \\
\hline
\end{tabular}

COVID-19 public health measures were present from March 2020 to September 2020.

ARR, attendance rate ratio; N/A, not applicable.

(ratio: 4.13) of the average monthly percentage of attendances due to dog bites.

COVID-19 public health measures were independently associated with a $66 \%$ increase in dog bite attendance rates in females and a $78 \%$ increase in males (table 2).

Females had the highest dog bite attendance rates from May to September. In contrast, male attendance rates were similar throughout the year except in March and November which displayed significantly lower rates. Female attendance rates showed similar attendance rates between toddlers and adolescents, with early and middle childhood showing the highest rates (peaking in early childhood), and infants the lowest. Male age attendance rates peaked in middle childhood. All male age groups had significantly higher rates than toddlers except infants who were significantly lower. To achieve the final model fit, the 'year' variable was excluded from both models. Both male and female models had good model fits with small residual differences (male model $\mathrm{p}=0.66$, female model $\mathrm{p}=0.94)$. No interaction terms were identified.

\section{DISCUSSION}

This study highlights that COVID-19 public health measures were associated with an increase in the number of paediatric dog bite emergency department attendances, potentially due to children spending more time at home, with greater exposure to dogs. Additionally, 
the demographics of children at risk of dog bites have remained the same during this period. These results can be used to underpin the need for an evidence-based approach to dog bite injury prevention strategies targeted at children and their guardians during this pandemic and future ones.

Following 4 years of stable monthly patterns of dog bite attendance, there was a sharp increase in dog bites and attendance percentage between April and July 2020: an effective tripling in dog bite attendances and quadrupling in percentage of attendances. This is confirmed by a clear statistical association between the period of COVID-19 public health measures and a rise in dog bite attendances.

The national lockdown (March to May 2020) ${ }^{15} 16$ saw a rapid reduction in overall emergency attendance levels, which reached their lowest in April. It was expected that overall attendance levels would decline as patients and parents were fearful of hospital-acquired COVID-19 and were told not to seek medical aid unless absolutely necessary. ${ }^{1-3}$ However, children continued to attend Alder Hey for dog bites, with no clear decrease in attendance, despite overall attendance numbers dramatically decreasing (figure 1).

Dog bite numbers did not dramatically increase until May, over a month into the lockdown period. The initial stable level of dog bites during lockdown was unexpected given another study reported a rapid increase in dog bite attendance as soon as their lockdown began. ${ }^{20}$ During the initial period, life satisfaction and happiness in adults declined, with anxiety levels raised. ${ }^{28}$ Rates of self-harm and domestic violence also rose. ${ }^{29} 30$ These studies highlight that in some households the normal emotional palette had been disrupted, and this could feasibly include dogs, who are viewed as family members. Dogs' routines also changed drastically during the first lockdown with $80 \%$ spending more time with children, and having less socialisation with other dogs and less exercise. ${ }^{31}$ Dog owners reported behavioural changes in their dogs and many reported a hesitancy to walk their dog due to COVID-19 infection risks. ${ }^{32}$ The observed time lag in attendances for bites may be due to a lag in household risk or a lag in attending hospitals.

Bite risk may not have increased immediately due to a range of reasons. It may have taken some time for dogs to exceed their tolerance threshold for behaviours directed towards them, and/or due to the accumulative effect of separate triggering experiences, ${ }^{33}$ particularly where there was greater activity occurring within homes during lockdown. Parental supervision of their children with dogs within the home is often limited, ${ }^{34}$ and this may have been further impacted during lockdown with parents having to juggle multiple conflicting demands on their time. In lockdown, there was also a fear of attending hospitals, ${ }^{35}$ so it is possible that less severe dog bite injuries were managed at home.

From May to July, the number of dog bite attendances increased faster than overall attendance number, leading to a higher percentage of attendances being due to dog bites. During this period, relaxation of public health restrictions and summer weather meant there was potentially more opportunity for children to be exposed to non-household dogs, providing another source of risk perhaps more absent previously. There may also have been increased exposure due to proliferation of $\mathrm{dog}$ adoptions and acquisition of 'pandemic puppies' as 2020 progressed. ${ }^{36}{ }^{37}$ Further, according to UK Kennel Club research, many new puppies were bought on impulse with little research ${ }^{38}$ Compounded by difficulty accessing professional advice due to 'emergency only' veterinary provision, ${ }^{39}$ and closure of training classes, many dogs acquired during 2020 may have had inadequate training and socialisation, which may result in a greater likelihood to biting.

August and September saw declining dog bite attendances and the percentage of attendances due to dog bites lowered, both measures returned to the normal range in September coincident with schools reopening, ${ }^{15} 16$ and likely resulted in children spending less time at home with dogs. In a study in Colorado, dog bite attendance numbers were not assessed beyond cessation of their lockdown, ${ }^{20}$ and it is possible that as public health measures eased, attendance rates would have returned to normal as our data have.

This study found that the sex and age profile of dog bite victims remained the same during the COVID-19 public health measures, in line with available international trauma data. ${ }^{13}$ Our data confirm dog bite seasonality, ${ }^{419}$ but to the best of our knowledge, this work is the first to describe sex differences related to dog bite seasonality, with dog bites to girls increasing during the summer, but not to boys; research is needed to understand why.

\section{Limitations}

The main limitation of these data is how representative they are of the wider UK population. Alder Hey Children's Hospital is one of Europe's largest paediatric hospitals, and the community it serves has one of the largest hospital admission rates for dog bites in the country. This research needs to be repeated at a national scale. For this audit, only case count and basic demographic information of the victims was captured. Further work exploring the association of COVID-19 public health measures with severity and anatomical location of the bites, and the context of the bite, is critically important if we are to understand why dog bites increased. The variable 'COVID-19 Public Health Measures' encompasses a complex range of measures varying in timing and likely impact. It is likely that multiple confounding and interacting factors led to the increase in dog bite attendance rates. It was felt that the pragmatic decision to choose a broad definition was justified. All our hypotheses as to why dog bites rose are speculative, and more research is needed. 


\section{CONCLUSIONS}

On 5 January 2021, the UK was once again told to 'Stay at Home'; this third COVID-19 lockdown is expected to last at least 2 months. Lockdowns across the world will continue until public health measures are successful in bringing the COVID-19 pandemic to an end. Until that time, lockdowns and school closures are likely to be associated with a rise in paediatric dog bites. The victims who attend emergency departments probably have the most severe injuries and represent only a portion of the bitten population. There will be potentially thousands of children who receive preventable and life-changing physical and psychological injuries. Urgent public health communication and education is needed to raise awareness of increased dog bite risk and promote safe interactions with dogs, thus ensuring that waves of dog bites do not follow strict COVID-19 public health measures.

\section{Twitter John S P Tulloch @JT_EpiVet}

Acknowledgements This work uses data provided by patients and collected by Alder Hey Children's Hospital as part of their care and support and would not be possible without access to these data. These data lead to valuable improvements in research and patient care. We would like to acknowledge the staff of Alder Hey Children's Hospital who provide incredible care and support to the communities they serve. Finally, we would like to thank the Merseyside Dog Safety Partnership (https://merseydogsafe.co.uk/) who provided excellent advice about our work, and who strive to help local communities keep their dogs, children, family and friends safe.

Contributors JSPT, SM, MR and CW conceptualised and designed the study. SM and VP collected, cleaned and anonymised the data. JSPT and RMC designed and performed the data analysis. JSPT and CW drafted the initial manuscript. All authors reviewed and revised the manuscript, and approved the final submitted manuscript.

Funding The authors have not declared a specific grant for this research from any funding agency in the public, commercial or not-for-profit sectors.

Disclaimer Dogs Trust had no influence on the design of the study; in the collection, analyses, or interpretation of data; in the writing of the manuscript, or in the decision to publish the results.

Competing interests RMC is employed by Dogs Trust, the UK's largest dog welfare charity.

Patient and public involvement Patients and/or the public were not involved in the design, or conduct, or reporting, or dissemination plans of this research.

\section{Patient consent for publication Not required.}

Ethics approval The study was defined as clinical audit and as such Research Ethics Committee review was not necessary. The audit was approved by the Alder Hey Children's NHS Foundation Trust (audit reference number: 6193).

Provenance and peer review Not commissioned; externally peer reviewed. Data availability statement Data are available upon reasonable request.

Open access This is an open access article distributed in accordance with the Creative Commons Attribution Non Commercial (CC BY-NC 4.0) license, which permits others to distribute, remix, adapt, build upon this work non-commercially, and license their derivative works on different terms, provided the original work is properly cited, appropriate credit is given, any changes made indicated, and the use is non-commercial. See: http://creativecommons.org/licenses/by-nc/4.0/.

ORCID iD

John S P Tulloch http://orcid.org/0000-0003-2150-0090

\section{REFERENCES}

1 Chaiyachati BH, Agawu A, Zorc JJ, et al. Trends in pediatric emergency department utilization after institution of coronavirus Disease-19 mandatory social distancing. J Pediatr 2020;226:274-7.
2 Keays G, Friedman D, Gagnon I. Injuries in the time of COVID-19. Health Promot Chronic Dis Prev Can 2020;40:336-41.

3 McDonnell T, Nicholson E, Conlon C, et al. Assessing the impact of COVID-19 public health stages on paediatric emergency attendance. Int J Environ Res Public Health 2020;17:6719.

4 Tulloch JSP, Owczarczak-Garstecka SC, Fleming KM, et al. English Hospital episode data analysis (1998-2018) reveal that the rise in dog bite hospital admissions is driven by adult cases. Sci Rep 2021;11:1767.

5 Morgan M, Palmer J. Dog bites. BMJ 2007;334:413-7.

6 Rollett R, Clancy R, Taib BG, et al. Re: not a plastic surgeon's best Friend: dog bites an increasing burden on UK plastic surgery services. J Plast Reconstr Aesthet Surg 2019;72:685-710.

7 Mannion CJ, Graham A. Dog bite injuries in hospital practice. Br J Hosp Med 2016;77:C165-8.

8 Loder RT. The demographics of dog bites in the United States. Heliyon 2019;5:e01360.

9 Lang ME, Klassen T. Dog bites in Canadian children: a five-year review of severity and emergency department management. CJEM 2005;7:309-14.

10 Langley RL. Human fatalities resulting from dog attacks in the United States, 1979-2005. Wilderness Environ Med 2009;20:19-25.

11 Raghavan M. Fatal dog attacks in Canada, 1990-2007. Can Vet J 2008;49:577-81.

12 Sarenbo S, Svensson PA. Bitten or Struck by dog: a rising number of fatalities in Europe, 1995-2016. Forensic Sci Int 2021;318:110592.

13 Jakeman M, Oxley JA, Owczarczak-Garstecka SC, et al. Pet dog bites in children: management and prevention. BMJ Paediatr Open 2020;4:e000726.

14 Boat BW, Dixon CA, Pearl E, et al. Pediatric dog bite victims: a need for a continuum of care. Clin Pediatr 2012;51:473-7.

15 Coronavirus act 2020 (C7). Available: https://www.legislation.gov.uk/ ukpga/2020/7/contents/enacted

16 The health protection (coronavirus, restrictions) (England) regulations, 2020. Available: https://www.legislation.gov.uk/uksi/ 2020/350/contents/made

17 Oliva JL, Johnston KL. Puppy love in the time of corona: dog ownership protects against loneliness for those living alone during the COVID-19 lockdown. Int J Soc Psychiatry 2020;2020:002076402094419.

18 Oxley JA, Christley R, Westgarth C. Contexts and consequences of dog bite incidents. J Vet Behav 2018;23:33-9.

19 Cornelissen JMR, Hopster H. Dog bites in the Netherlands: a study of victims, injuries, circumstances and aggressors to support evaluation of breed specific legislation. Vet $J$ 2010;186:292-8.

20 Dixon CA, Mistry RD. Dog bites in children surge during coronavirus Disease-2019: a case for enhanced prevention. J Pediatr 2020;225:231-2.

21 Merseyside dog safety partnership. campaign: help fight COVID-19 by staying safe around dogs, 2020. Available: https:// merseydogsafe.co.uk/help-fight-covid-19-by-staying-safe-arounddogs/ [Accessed 14 Jan 2021].

22 Jacoby WG. Loess: a nonparametric, graphical tool for depicting relationships between variables. Elect Stud 2000;19:577-613.

23 Hyndman RJ, Khandakar Y. Automatic Time Series Forecasting: The forecast Package for R. J Stat Softw 2008;27.

24 Wickham H, Averick M, Bryan J, et al. Welcome to the Tidyverse. JOSS 2019;4:1686.

25 Hyndman R, Athanasopoulos G. Forecasting: principles and practice. Melbourne, Australia: OTexts:, 2018.

26 Abdel-Rahman SM, Amidon GL, Kaul A, et al. Summary of the National Institute of child health and human Development-best pharmaceuticals for children act pediatric formulation initiatives Workshop-Pediatric biopharmaceutics classification system Working group. Clin Ther 2012;34:S11-24.

27 World Health Organization. World health statistics 2019: monitoring health for the SDGs, sustainable development goals. Available: https://apps.who.int/iris/handle/10665/324835 [Accessed 14 Jan 2021].

28 Office for National Statistics. Coronavirus and the social impacts on great Britain, 2021. Available: https://www.ons.gov.uk/peoplepo pulationandcommunity/healthandsocialcare/healthandwellbeing/ bulletins/coronavirusandthesocialimpactsongreatbritain/ 8january2021 [Accessed 9 Jan 2021].

29 Olding J, Zisman S, Olding C, et al. Penetrating trauma during a global pandemic: changing patterns in interpersonal violence, self-harm and domestic violence in the Covid-19 outbreak. Surgeon 2021;19:e9-13.

30 lob E, Steptoe A, Fancourt D. Abuse, self-harm and suicidal ideation in the UK during the COVID-19 pandemic. Br J Psychiatry 2020;217:543-6. 
31 Christley RM, Murray JK, Anderson KL, et al. Impact of the first COVID-19 Lockdown on management of PET dogs in the UK. Animals 2021;11:5.

32 Applebaum JW, Tomlinson CA, Matijczak A, et al. The concerns, difficulties, and stressors of caring for pets during COVID-19: results from a large survey of U.S. PET owners. Animals 2020;10:1882-14.

33 Mills DS, Braem Dube M, Zulch H. Stress and pheromonatherapy in small animal clinical behaviour. Chichester: Wiley Blackwell, 2013.

34 Arhant C, Landenberger R, Beetz A, et al. Attitudes of caregivers to supervision of child-family dog interactions in children up to 6 years-An exploratory study. J Vet Behav Clin Appl Res 2016;14:10-16.

35 Franchini S, Spessot M, Landoni G, et al. Stranger months: how SARS-CoV-2, fear of contagion, and lockdown measures impacted attendance and clinical activity during February and March 2020 at an urban emergency department in Milan. Disaster Med Public Health Prep 2020:1-10.

36 Morgan L, Protopopova A, Birkler RID, et al. Human-dog relationships during the COVID-19 pandemic: booming dog adoption during social isolation. Humanit Soc Sci Commun 2020;7:155

37 The Kennel Club. Breed registration statistics. Available: https:// www.thekennelclub.org.uk/registration/breed-registration-statistics/ [Accessed 14 Jan 2021].

38 The Kennel Club. The COVID-19 puppy boom - one in four admit impulse buying a pandemic puppy.. Available: https://www. thekennelclub.org.uk/media-centre/2020/august/the-covid-19puppy-boom-one-in-four-admit-impulse-buying-a-pandemic-puppy/ [Accessed 14 Jan 2021].

39 RCVS. Coronavirus (Covid-19). Available: https://www.rcvs.org. uk/setting-standards/advice-and-guidance/coronavirus-covid-19/ [Accessed 20 Jan 2021]. 